\title{
How well do blood flow imaging and collaterals on angiography predict brain at risk?
}

David S. Liebeskind, MD

Nerses Sanossian, MD

Correspondence \& reprint requests to Dr. Liebeskind: davidliebeskind@yahoo.com

\section{ABSTRACT}

As endovascular therapy emerges as a principal approach to restore blood flow in the setting of acute stroke, better methods of patient selection need to be developed. Noninvasive studies of blood flow and angiographic results acquired prior to endovascular therapy may help determine areas of brain at risk of infarction and hemorrhagic transformation, both largely determined by the severity of cerebral ischemia. Pathophysiologic measures of collateral flow and perfusion that characterize ischemic severity prior to revascularization may optimize acute stroke decisionmaking, currently driven by arbitrary time parameters derived from population studies devoid of imaging. Neurology ${ }^{\circledR}$ 2012;79 (Suppl 1):S105-S109

\section{GLOSSARY}

ASITN/SIR = American Society of Intervention and Therapeutic Neuroradiology/Society of Interventional Radiology; $\mathbf{C B F}=$ cerebral blood flow; $\mathbf{C B V}=$ cerebral blood volume; $\mathbf{C T A}=$ computed tomographic angiography; $\mathbf{C T P}=$ computed tomographic perfusion; $\mathbf{M C A}=$ middle cerebral artery; MRA = magnetic resonance angiography; $\mathbf{P W I}=$ perfusionweighted MRI; SIR = Society of Interventional Radiology; SVIN = Society of Vascular and Interventional Neurology; TTP $=$ time to peak

The last decade has seen numerous advances in neuroimaging and acute ischemic stroke therapies, ${ }^{1,2}$ with the emergence of endovascular therapy as a principal approach to blood flow restoration. Defining the optimal conditions for reperfusion that will avert further neurologic injury without causing hemorrhagic transformation is very important to the development of endovascular treatment. Noninvasive multimodal CT or MRI techniques and angiography performed prior to endovascular therapy can provide a wealth of information regarding collateral blood flow, which is critical to patient selection, prediction of clinical outcome, and avoidance of complications. ${ }^{3}$

Measures of collateral flow on noninvasive modalities and angiography may help to define specific regions of brain at risk of infarction and hemorrhage. Collaterals sustain ischemic regions when the primary source of arterial inflow is blocked. Both ischemia and reperfusion, determinants of outcome and hemorrhagic transformation, are influenced by collaterals. Hemorrhage likely results from a combination of severe ischemia followed by reperfusion in regions where collaterals have not offset deleterious changes in downstream resistance. ${ }^{4,5}$ Collaterals and perfusion status may be detailed prior to intervention with multimodal CT or MRI and angiography. Application of these diagnostic tools may optimize patient selection and guide therapy in acute ischemic stroke.

The recommendations presented in this manuscript are the result of the Society of Vascular and Interventional Neurology (SVIN) Roundtable on Endovascular Therapy for Acute Ischemic Stroke, held in Chicago, Illinois, on July 25, 2008. SVIN is an organization that focuses on both the endovascular approaches to acute ischemic stroke and the peri-procedural management of these cases.

From the UCLA Stroke Center and Department of Neurology (D.S.L.), University of California, Los Angeles; and Department of Neurology (N.S.), University of Southern California, Los Angeles.

Study funding: Supported by grant K23NS054084 (D.S.L.) from the National Institute of Neurological Disorders and Stroke and grant $0765127 \mathrm{Y}$ (N.S.) from the American Heart Association.

Go to Neurology.org for full disclosures. Disclosures deemed relevant by the authors, if any, are provided at the end of this article. 
IMAGING PRIOR TO ANGIOGRAPHY In many centers, angiography proceeds directly after a noncontrast CT scan is acquired. The role of a noncontrast head CT scan is to reveal overt contraindications to thrombolysis or thrombectomy. This is the most time-sensitive, conventional approach and has been used for decades. Although multimodal imaging with CT or MRI provides more information regarding vessel patency and downstream perfusion, the role of this additional information in patient selection remains unclear. There is no consensus as to how this additional information, which includes features of collateral status, should be incorporated in decision-making for acute treatment. ${ }^{2}$ This additional information comes at the potential cost of resources and time.

Almost every neuroimaging modality can be used in the setting of acute stroke to reveal features of collateral flow. ${ }^{6}$ Transcranial Doppler ultrasonography may reveal flow diversion to collateral routes and even signatures of retrograde flow in leptomeningeal routes. ${ }^{7,8}$ CT and MRI may reveal ischemic lesion patterns that denote collateral preservation of other areas, with angiographic findings of collateral patency and perfusion changes that reflect compensation via these routes. ${ }^{3}$ For example, a noncontrast CT that demonstrates isolated loss of the insular ribbon despite severe neurologic deficit may indicate robust collaterals despite MCA occlusion. The choice of imaging modality and which information to use in decision-making must be better defined.

MRI and CT-based imaging protocols have been developed to better assess collaterals and perfusion, drawing upon advances in imaging technology. Methods of obtaining computed tomographic angiography (CTA) and magnetic resonance angiography (MRA) or CT perfusion (CTP) and perfusionweighted MRI (PWI) have not used equivalent standards. ${ }^{2}$ For example, it is misleading to directly compare a CT-based approach utilizing cerebral blood volume (CBV) with an MRI-based approach utilizing time-to-peak (TTP) data from PWI. ${ }^{9}$ Simultaneous acquisition of CT and MRI is exceedingly challenging and likely unnecessary. The choice of modality (i.e., CT or MRI) should be individualized to site-specific availability and timeliness. In either case, selection of cases for endovascular therapy with CT or MRI will ultimately depend on and complement findings at the time of angiography. Perfusion and tissue features that suggest sustained perfusion beyond an occluded arterial segment may be sufficient to proceed to revascularization.

We believe that obtaining perfusion/collateral imaging prior to angiography is important and will help to better define patients likely to benefit from reperfusion. Acute stroke is a dynamic process that changes from minute to minute, with perfusion and collateral status depending on factors such as head position and other hemodynamic determinants such as blood pressure. ${ }^{10}$ The hallmarks of collateral perfusion are delay and dispersion. ${ }^{6}$ Delay alone may not be harmful, but dispersion evident from CBV may indicate important changes in the brain vasculature. Additional complexity is added by the fact that CBV initially increases before decreasing, at later stages leading to ultimate cerebral blood flow (CBF) demise. It should also be remembered that these features of collateral perfusion have been primarily derived for studies of MCA occlusion and other territorial insults or vascular lesions; such variables may differ in a particular acute stroke case.

DOES NONINVASIVE PERFUSION IMAGING MATCH UP WITH ANGIOGRAPHY? Angiography and noninvasive imaging provide different yet complementary information. Recently we have noted that collaterals on noninvasive perfusion imaging may not correlate directly with angiographic collaterals, yet both are important in predicting outcome. ${ }^{11}$ Angiography has the ability to define specific vascular segments due to the more selective injection of contrast, whereas CT or MRI perfusion parameters reflect the entire bolus, including all vascular segments, from arterial inflow routes, through capillaries, and into the venous system. These noninvasive studies, however, cannot definitively isolate one circulatory phase from another. New techniques such as perfusion angiography (figure 1) may help reconcile these differences. ${ }^{12}$

Obtaining an angiographic assessment of collaterals prior to endovascular reperfusion is an important step. Collateral surveys may entail aortic arch runs, vertebral injections, or solely ipsilateral parent artery views such as a selective internal carotid injection in MCA occlusion. Often, more thorough assessments of collateral blood flow with angiography prior to intervention are viewed as purely academic and are not obtained, yet collaterals have been demonstrated to be one of the most potent predictors of arterial recanalization and clinical outcome. ${ }^{13}$ Quantification or characterization of collaterals on angiography may use one of several scales, ${ }^{14}$ such as the American Society of Intervention and Therapeutic Neuroradiology/ Society of Interventional Radiology (ASITN/SIR) scale (table, figure 2). This scale describes collateral filling of the ischemic territory, measuring arterial vigor and even dispersion of flow long into the venous phase. This scale is not specific to the MCA but may be used in any territorial occlusion.

Direct comparison of collaterals by means of the ASITN/SIR scale with MRI perfusion data reflects 

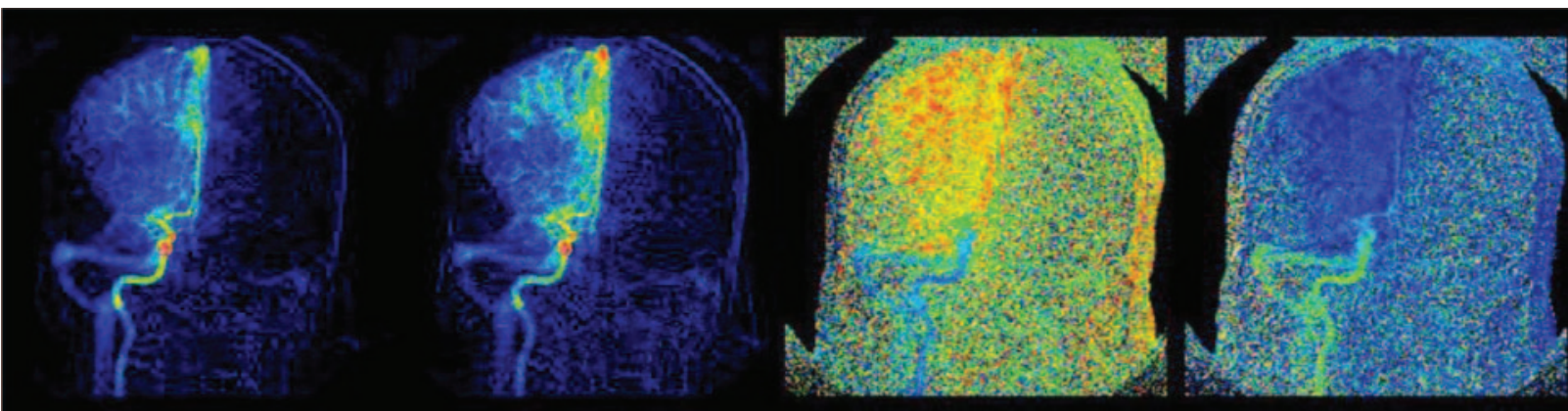

CBF

CBV

MTT

CPP

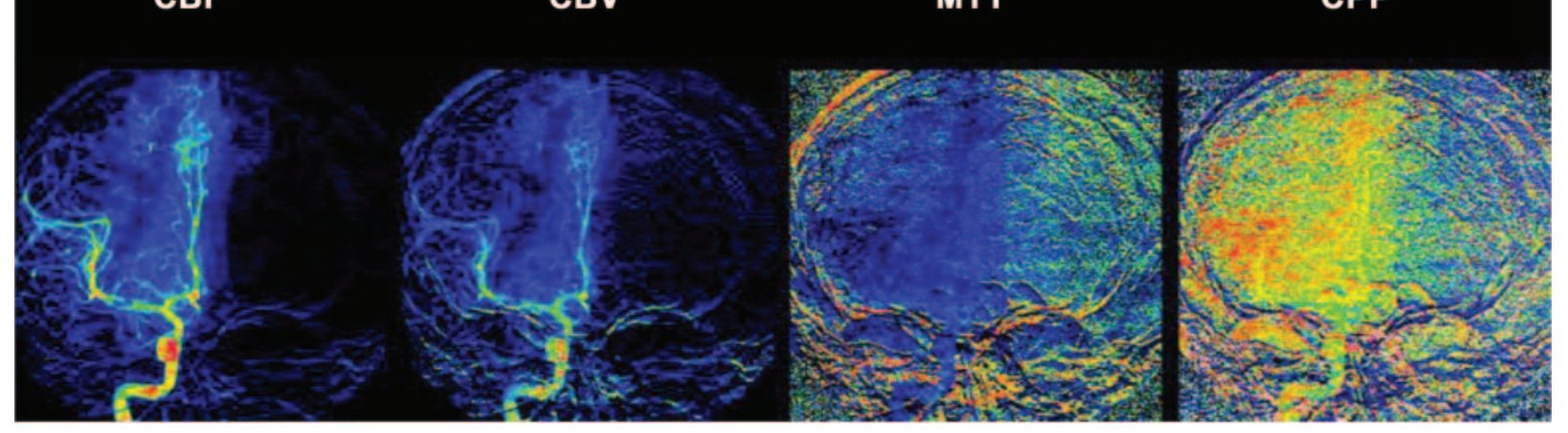

$\mathrm{CBF}=$ cerebral blood flow; $\mathrm{CBV}=$ cerebral blood volume; $\mathrm{CPP}=$ cerebral perfusion pressure; $\mathrm{MTT}=$ mean transit time.

the different information obtained by each. The ASITN/SIR scale reflects arterial predominance at angiography, which may be distinct from the more generalized information provided on dedicated perfusion imaging with CT or MRI. ${ }^{11}$ Across cases with robust collaterals measured by angiography, perfusion measures on MRI, such as $\mathrm{T}_{\text {max }}$ (time at which plasma concentration peaks), vary considerably. ${ }^{15}$ This variability indicates that despite interest in a sin-

\begin{tabular}{|l|l|}
\hline Table & $\begin{array}{l}\text { The ASITN/SIR Collateral Flow } \\
\text { Grading System for determining } \\
\text { angiographic collateral grade on } \\
\text { pretreatment angiography }\end{array}$ \\
ASITN/SIR \\
collateral grade
\end{tabular}

Abbreviation: ASITN/SIR = American Society of Intervention and Therapeutic Neuroradiology/Society of Interventional Radiology. gle ideal noninvasive perfusion parameter, multiparametic approaches are more likely to optimize patient selection. Often the sole perfusion measure obtained at the scanner is TTP, which may easily mistake areas previously described as benign oligemia with true ischemic penumbra. ${ }^{15}$

NONINVASIVE PERFUSION DEFINITIONS OF AT-RISK One of the principal challenges of noninvasive approaches to measuring perfusion is differentiating at-risk brain tissue from benign oligemia, areas of abnormal perfusion that are not at risk of infarction. There is currently no consensus as to where the boundary between at-risk areas of brain and benign oligemia resides. For example, in a typical scenario, the entire MCA territory may be abnormal in imaging with perfusion MRI TTP, but only a portion will go on to infarct. Multiparametric imaging may hold the key to improved prediction, but it may be limited by the existence of many factors that influence infarction, which go unaccounted for. ${ }^{15}$ These include blood pressure and other hemodynamic influences at the time of the study. Another factor limiting prediction is the reliance on parameters of arterial blood flow arrival. Collateral perfusion, blood flow, and sustenance of at-risk tissue have much to do with downstream resistance and the microvasculature, aspects which have not yet received much consideration. There must be a shift in inter- 

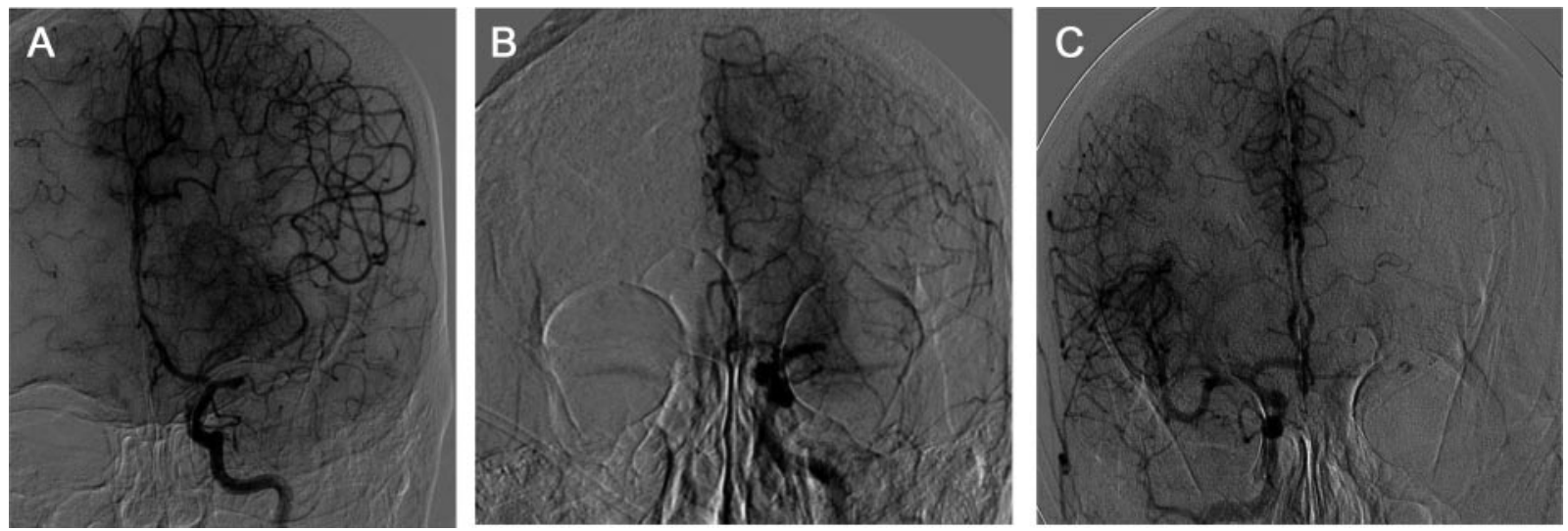

Excellent grade 4 collaterals, which fill the entire middle cerebral artery (MCA) territory (A); grade 3 collaterals (B), filling most of the MCA territory on an ipsilateral internal carotid artery (ICA) injection; and grade 2 collaterals (C), seen filling the MCA territory though the anterior communicating artery and anterior cerebral artery on a contralateral ICA injection.

ventional stroke therapy, away from the goal of simply opening an artery to re-establishing cerebral blood flow. It is relatively straightforward to treat an occluded cerebral artery yet more difficult to predict effects on downstream flow and tissue response. Selection of stroke patients for endovascular therapy must not be based on the simplistic "go or no-go" approach from the start of the procedure. Rather, selection should be based on re-evaluation at regular intervals throughout endovascular therapy.

Let us consider the case of a terminal carotid occlusion successfully lysed with intra-arterial therapy leading to a residual M2 occlusion. The decision to treat further or to stop may depend on numerous factors and merits reconsideration. A significant improvement in blood flow may have been attained, with much-improved collateral flow. Stopping at this point may reasonably balance the need to offset ischemia without reperfusing areas prone to hemorrhage. The Interventional Management of Stroke (IMS)-3 clinical trial includes re-evaluation of cerebral flow every 15 minutes with repeat angiograms. ${ }^{16}$

SUMMARY Endovascular treatment of acute stroke holds great promise in improving outcomes and saving lives yet requires greater resource allocation. One barrier to greater implementation of endovascular treatment is the lack of clear consensus regarding which patients are most likely to benefit from this treatment approach. Imaging-based selection, which incorporates an understanding of the physiologic changes in brain perfusion and collaterals, may help in identification of eligible patients, maximize clinical benefit, and improve allocation of resources.

Recommendations. Imaging prior to angiography. Ischemic stroke is a disorder of ischemia, not only throm- bosis, and measurement of perfusion is therefore critical. Dedicated perfusion techniques or indirect information regarding downstream collateral sustenance will likely predict evolving ischemic damage before irreversible injury and hemorrhagic transformation. Perfusion imaging or noninvasive measures of collaterals (e.g., CTA/MRA source images) should be obtained and systematically evaluated before moving to the angiography suite.

Does noninvasive perfusion imaging match up with angiography? More studies are required to understand the relationship between specific compartments of the cerebral circulation and perfusion in acute stroke. Such studies will highlight the role of arterial inflow via anastomoses and expand upon the key features of microvascular ischemia and downstream compensatory venous changes.

Noninvasive perfusion definitions of at-risk. Multiparametric perfusion measures and novel imaging features derived from these studies (e.g., flow heterogeneity, permeability) warrant further investigation. These may provide more complete information regarding compensatory changes and the risks inherent to each decision pathway for endovascular therapy.

Angiographic predictors of tissue at risk. Angiography should be valued as more than a mere arterial roadmap to extract thrombus. The incredible expanse of information on angiography regarding specific vascular segments and perfusion changes should be harnessed with novel approaches such as perfusion angiography.

\section{AUTHOR CONTRIBUTIONS}

Dr. Liebeskind: drafting/revising the manuscript, study concept or design, acquisition of data, study supervision or coordination. Dr. Sanossian: drafting/revising the manuscript, study concept or design, analysis or interpretation of data. 


\section{DISCLOSURE}

Dr. Liebeskind has served as a consultant for Concentric Medical and CoAxia and has received research support from the National Institutes of Health. Dr. Sanossian has served on the speaker bureaus for Boehringer Ingelheim Pharmaceuticals. Go to Neurology.org for full disclosures.

Received July 10, 2011. Accepted in final form September 13, 2011.

\section{REFERENCES}

1. Kim D, Liebeskind DS. Neuroimaging advances and the transformation of acute stroke care. Semin Neurol 2005; 25:345-361

2. Wintermark M, Albers GW, Alexandrov AV, et al. Acute stroke imaging research roadmap. AJNR Am J Neuroradiol 2008;29:e23-e30.

3. Liebeskind DS. Collaterals in acute stroke: beyond the clot. Neuroimaging Clin N Am 2005;15:553-573.

4. Liebeskind DS. Aortic occlusion for cerebral ischemia: from theory to practice. Curr Cardiol Rep 2008;10:31-36.

5. Liebeskind DS, Bang OY, Ovbiagele B, et al. Collateral flow markedly reduces hemorrhagic transformation in acute stroke. Stroke 2007;38:468. Abstract.

6. Liebeskind DS. Collateral circulation. Stroke 2003;34: 2279-2284

7. Kim Y, Sin DS, Park HY, Park MS, Cho KH. Relationship between flow diversion on transcranial Doppler sonography and leptomeningeal collateral circulation in patients with middle cerebral artery occlusive disorder. J Neuroimaging 2009;19:23-26.
8. Zanette EM, Fieschi C, Bozzao L, et al. Comparison of cerebral angiography and transcranial Doppler sonography in acute stroke. Stroke 1989;20:899-903.

9. Hassan AE, Zacharatos H, Chaudhry SA, et al. Agreement in endovascular thrombolysis patient selection based on interpretation of presenting CT and CT-P changes in ischemic stroke patients. Neurocrit Care 2012;16:88-94.

10. Liebeskind DS. Collateral therapeutics for cerebral ischemia. Expert Rev Neurother 2004;4:255-265.

11. Bang OY, Saver JL, Buck BH, et al. Impact of collateral flow on tissue fate in acute ischaemic stroke. J Neurol Neurosurg Psychiatry 2008;79:625-629.

12. Liebeskind DS, Szilagyi G, Black SE, Buck BH. Perfusion angiography: a novel technique for characterization of perfusion in cerebral ischemia. Stroke 2008;39:564. Abstract.

13. Jo KD, Saver JL, Starkman S, et al. Predictors of recanalization with mechanical thrombectomy for acute ischemic stroke. Stroke 2008;39:599. Abstract.

14. Liebeskind DS, Nogueira RG. Angiographic scales in acute ischemic stroke: the MERCI/Multi MERCI experience. Stroke 2008;39:602. Abstract.

15. Liebeskind DS, Alger JR, Bang OY, et al. Benign oligemia reflects collateral perfusion: MRI and angiography of low perfusion hyperemia in humans. Stroke 2008;39:577. Abstract.

16. Khatri P, Hill MD, Palesch YY, et al. Methodology of the Interventional Management of Stroke III Trial. Int J Stroke 2008;3:130-137. 


\title{
Neurology
}

\author{
How well do blood flow imaging and collaterals on angiography predict brain at risk? \\ David S. Liebeskind and Nerses Sanossian \\ Neurology 2012;79;S105-S109 \\ DOI 10.1212/WNL.0b013e3182695904
}

This information is current as of September 24, 2012

Updated Information \&
Services

References

Subspecialty Collections

Permissions \& Licensing

Reprints including high resolution figures, can be found at:

http://n.neurology.org/content/79/13_Supplement_1/S105.full

This article cites 16 articles, 4 of which you can access for free at: http://n.neurology.org/content/79/13_Supplement_1/S105.full\#ref-list1

This article, along with others on similar topics, appears in the following collection(s):

All Cerebrovascular disease/Stroke

http://n.neurology.org/cgi/collection/all_cerebrovascular_disease_strok e

All Imaging

http://n.neurology.org/cgi/collection/all_imaging

Information about reproducing this article in parts (figures,tables) or in its entirety can be found online at:

http://www.neurology.org/about/about_the_journal\#permissions

Information about ordering reprints can be found online:

http://n.neurology.org/subscribers/advertise

Neurology ${ }^{\circledR}$ is the official journal of the American Academy of Neurology. Published continuously since 1951, it is now a weekly with 48 issues per year. Copyright Copyright $@ 2012$ by AAN Enterprises, Inc.. All rights reserved. Print ISSN: 0028-3878. Online ISSN: 1526-632X.

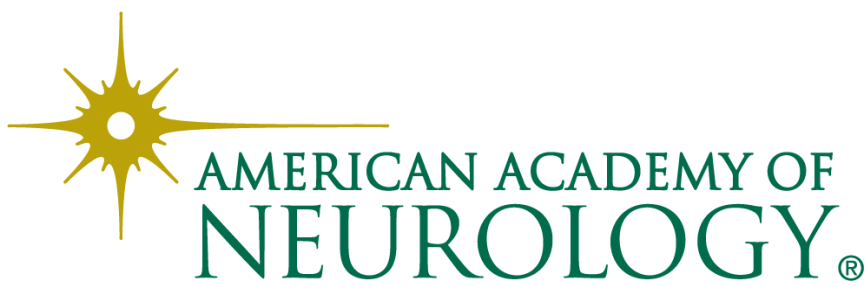

